
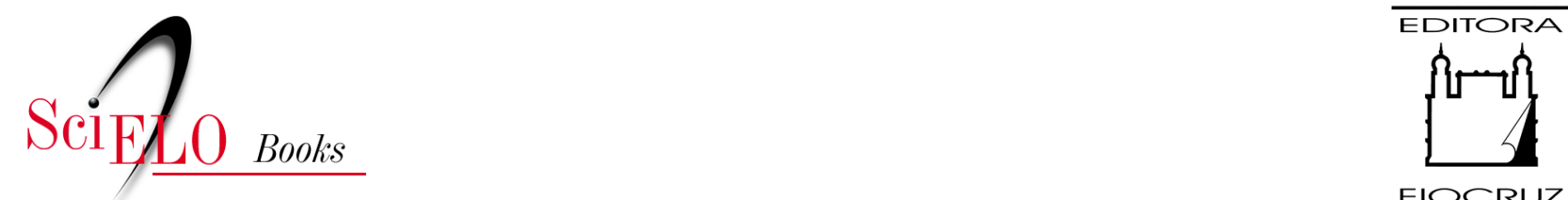

FIOCRUZ

\title{
Políticas públicas de saúde e a organização do SUS
}

\author{
Gloria Regina da Silva e Sá \\ Paula de Castro Nunes \\ Omara Machado Araújo de Oliveira \\ Grácia Maria de Miranda Gondim
}

\section{SciELO Books / SciELO Livros / SciELO Libros}

SÁ, G.R.S., NUNES, P.C., OLIVEIRA, O.M.A., and GONDIM, G.M.M. Políticas públicas de saúde e a organização do SUS. In: SILVA, M.N., FLAUZINO, R.F., GONDIM, G.M.M., eds. Rede de frio: fundamentos para a compreensão do trabalho [online]. Rio de Janeiro: Editora FIOCRUZ, 2017, pp. 51-82. ISBN: 978-65-5708-091-7. https://doi.org/10.7476/9786557080917.0004.

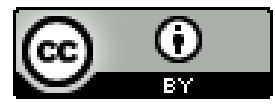

All the contents of this work, except where otherwise noted, is licensed under a Creative Commons Attribution 4.0 International license.

Todo o conteúdo deste trabalho, exceto quando houver ressalva, é publicado sob a licença Creative Commons Atribição 4.0.

Todo el contenido de esta obra, excepto donde se indique lo contrario, está bajo licencia de la licencia Creative Commons Reconocimento 4.0. 


\section{Políticas públicas de saúde e a organização do SUS}

Gloria Regina da Silva e Sá, Paula de Castro Nunes, Omara Machado Araújo de Oliveira e Grácia Maria de Miranda Gondim

A política pública entendida como o conjunto de ações realizadas pelo Estado e seus agentes, com a participação ou não da sociedade, visa garantir os direitos sociais previstos em lei. Atualmente, estão no âmbito das políticas públicas: a educação, a saúde, a segurança, a habitação, o transporte, a transferência de renda, a segurança alimentar, entre outras (TEIXEIRA, 2001; PAIM, 2003).

As políticas públicas de saúde como parte das políticas de proteção social se constituem estratégias para minimizar as desigualdades e injustiças sociais decorrentes do modo de produção capitalista, que exclui e põe à margem da produção e dos seus benefícios centenas de milhares de pessoas que vivem na miséria ou em condições degradantes de vida. São propostas para atender às reivindicações da população e dos movimentos sociais por melhores condições de vida e trabalho.

Neste capítulo, estão organizados temas e conteúdos que possibilitarão compreender as políticas públicas de saúde e os modelos assistenciais que culminaram com a construção do Sistema Único de Saúde (SUS), seus princípios e diretrizes; as normas que orientam sua operacionalização e a organização de diferentes redes para atender a população - atenção, vigilância e de promoção da saúde; bem como o movimento que o consolidou como uma saída à crise do sistema nacional de saúde nos anos 1970-1980. Esses são conhecimentos fundamentais para que o trabalhador da rede de frio de imunobiológicos se identifique como agente desse sistema, reconhecendo que o resultado de sua ação pode efetuar mudanças significativas, tanto no âmbito do seu trabalho como no cotidiano dos serviços de saúde junto aos usuários. 


\section{O início das políticas públicas de saúde no Brasil}

As políticas públicas de saúde no Brasil se constituíram em um eficaz instrumento de controle político e social do Estado sobre a classe trabalhadora formal. Dentre outros objetivos, destaca-se o de apoiar a estruturação do sistema produtivo do país, relativizando as contradições inerentes ao próprio sistema e minimizando os efeitos nocivos das atividades econômicas sobre a sociedade (SILVA, 1996).

A realização do controle de portos e estradas de ferro contribuía como uma barreira, a qual minimizava a entrada e circulação de mercadorias (produtos diversos) que intervinham na economia do país. Àquela época, a economia apresentava, fundamentalmente, um modelo agroexportador de itens como café, açúcar etc. Além disso, tal controle permitia conter o fluxo das doenças de uma região para a outra, ou, em alguns casos, de países estrangeiros para o Brasil.

Repare como as ações de vacinação estão entranhadas nas políticas públicas de saúde do país.
No século XX, teve início um conjunto de políticas públicas de saúde voltadas para atender e dar resposta a inúmeros problemas que deveriam ser enfrentados àquela época, decorrentes do processo incipiente de urbanização e industrialização em curso em algumas cidades de importância nacional.

A mobilidade interna (migração) e a externa (imigração) propiciaram a introdução de doenças e hábitos novos trazidos por pessoas, animais, vetores e alimentos, os quais afetavam a saúde da população, em especial os trabalhadores, acarretando prejuízo para a produção e o consumo de bens e serviços. Por isso, se fazia necessário o controle das estradas de ferro e dos portos, onde ocorriam as trocas, para manter a saúde das pessoas e dos lugares.

A vacinação obrigatória e, depois, as campanhas sanitárias podem ser entendidas como esboços dessas políticas públicas, por sua especial importância para a economia agroexportadora, pelo controle dos portos e das estradas de ferro. São dessa época as campanhas contra (POSSAS, 1981):

a varíola, cujo principal marco foi a lei de vacinação obrigatória, em 1904;

* febre amarela, por meio da caça aos mosquitos e seus criadouros; e * a peste bubônica, por meio da caça aos ratos transmissores da doença.

Algumas políticas de saúde voltadas para o controle e a vigilância foram sendo, inicialmente, impostas à população, que se rebelou e dificultou o trabalho da saúde pública por não entender ou não concordar com a ação arbitrária do Estado sobre suas vidas. A Revolta da Vacina é um exemplo: uma insurreição ocorrida no Rio de Janeiro, em 1904, como reação popular à campanha da vacinação obrigatória contra a varíola, que foi posta em prática pelo sanitarista Oswaldo Cruz.

Os problemas emergentes dessa época resultaram na reformulação de órgãos federais, tendo como consequência, na saúde, a criação do Departamento Nacional de Saúde Pública (DNSP), em 1921. O DNSP se encarregava do saneamento urbano e rural, da higiene industrial e dos serviços de higiene materno-infantil, em especial (GUIMARÃES, 1984). 
A Lei Eloy Chaves, de 1923, que criou as Caixas de Aposentadorias e Pensão (CAPs), foi um marco nas políticas sociais no Brasil. Ela decorre do movimento grevista operário, e não de setores do Estado, sendo as CAPs organizadas por empresas, geridas e financiadas por trabalhadores e empresários. Destinavam-se a oferecer benefícios pecuniários, como os serviços de saúde destinados a alguns empregados que tinham importância estratégica para a economia. Como vantagens para seus segurados, as CAPs ofereciam seguridade social, serviço médico-assistencial e medicamentos (RONCALLI, 2003).

Em 1930, Getúlio Vargas assumiu a Presidência da República, suspendeu a Constituição de 1891 e governou por meio de decretos até 1934, quando o Congresso Constituinte aprovou uma nova Constituição. Nesse período, perseguiu seus opositores e os principais líderes sindicais do país, principalmente depois de 1937, quando instituiu a ditadura do Estado Novo. Até 1945 centralizou a máquina governamental e, também, impediu reivindicações sociais, recorrendo a medidas populistas, em que o Estado se colocava como tutor da sociedade, provendo o que julgava ser necessário e suficiente aos cidadãos (BERTOLLI FILHO, 1996). As políticas sociais foram suas armas para justificar, diante do povo, sua forma autoritária de agir, tentando amenizá-la pela aparência "bondosa" como presidente.

Vargas promoveu uma ampla reforma política e administrativa. Criou o Ministério do Trabalho, com os sindicatos vinculados, e efetuou uma ampla legislação trabalhista. Com isso, regulamentou a relação entre capital e trabalho, e o Estado sedimentou as bases necessárias para que as condições econômicas do país saltassem para uma nova etapa - a industrialização (CEFOR, [199-]).

É dessa época, também, a criação do Ministério da Educação e Saúde Pública (MESP), que possibilitou a centralização das políticas públicas (especialmente nos anos 1940) sob a coordenação do governo federal. Dentre as políticas sociais criadas no período compreendido entre 1930 e 1934, destacam-se os Institutos de Aposentadoria e Pensões (IAPs, em 1933), por se caracterizar como novo modelo de organização previdenciária substitutiva das antigas CAPs. Esse novo modelo era organizado por categoria profissional e administrado pelo Estado (GONDIM, 2011).

É importante compreender a intencionalidade e o contexto em que são formuladas algumas políticas públicas, que se articulam com realidades muito maiores do que aquilo ao qual se destinam.
Benefícios pecuniários Pecuniário é um termo que se refere a dinheiro. Assim, benefícios pecuniários referem-se a "vantagens em dinheiro", as quais são concedidas a funcionários ou associados de determinada empresa ou órgão - público ou privado. Para ter direito a esse tipo de vantagem, o indivíduo deve contribuir para a instituição ou órgão por determinado período de tempo, de modo a ter direito a remuneração ou prêmio. Alguns exemplos desses benefícios são: salário-família, auxílio-natalidade, entre outros (BRASIL, 2007). 
É o caso do Serviço Especial de Saúde Pública (SESP), criado na década de 1940, durante a Segunda Guerra Mundial, para dar suporte ao esforço de guerra na Amazônia, o qual cumpria um papel estratégico, ao produzir borracha para a indústria bélica. Suas ações foram fundamentais para a manutenção da saúde dos trabalhadores da borracha, evitando o adoecimento destes e a diminuição do esforço de guerra na região, bem como para o enfrentamento da malária na Região Norte, na década de 1950, por meio de pesquisas de doenças tropicais e da educação sanitária.

Na sequência dos acontecimentos, em 1953, foi instituído o Ministério da Saúde (MS), com um aporte de recurso insignificante, atestando o pouco caso que o governo Vargas dedicava à saúde da população. Em 1956, com o argumento de promover a educação sanitária para a população rural em áreas remotas do país, criou-se o Departamento Nacional de Endemias Rurais (DNERU).

No período de 1964 a 1985, o país viveu a ditadura militar. Esse tempo foi marcado por um regime de exceção, com uma série de medidas antidemocráticas e ações coercitivas, que iam do fechamento do Congresso Nacional até a suspensão das liberdades individuais.

Em 1966, os IAPs foram unificados no Instituto Nacional de Previdência Social (INPS), originando um sistema previdenciário para todos os brasileiros que estivessem inseridos no mercado de trabalho, aglutinando formas de assistência social relacionadas à área da saúde.

Se quiser saber um pouco mais sobre o histórico das políticas públicas de saúde do nosso país, assista ao filme Políticas de saúde no Brasil - um século de luta pelo direito à saúde, uma produção da Universidade Federal Fluminense, que se encontra disponível em https://www.youtube.com/ watch?v=Kbo7YrhsE84
Nesse período, o sistema nacional de saúde brasileiro viveu uma crise que se agudizou por insuficiência de recursos humanos, má distribuição espacial da rede de serviços, falta de coordenação, inadequação do cuidado às necessidades da população e às demandas dos profissionais de saúde. Ineficiência e ineficácia marcavam as ações que não atendiam ao perfil de adoecimento e morte que se delineavam. Além disso, somente parte da população tinha acesso a esse sistema.

Havia, portanto, muita insatisfação por parte da população, dos profissionais de saúde, pesquisadores, estudantes e outras instituições da sociedade civil, que propunham uma série de saídas para resolver os problemas identificados e buscar a redemocratização do país e a universalização do direito à saúde. Nasceu, assim, o Movimento da Reforma Sanitária Brasileira (MRSB), que se colocava como a base para a instituição do Sistema Único de Saúde (SUS). 
Todas as mudanças originadas nas estruturas da saúde ao longo desse tempo, além de demandas político-institucionais, também respondem a duas questões principais: o entendimento do conceito de saúde e os modelos assistenciais que orientam as práticas e a organização dos sistemas de saúde.

\section{O Movimento da Reforma Sanitária: origens do SUS}

O Movimento da Reforma Sanitária Brasileira (MRSB) representou um divisor de águas na política nacional de saúde. Na ocasião, a sociedade brasileira se mobilizava em torno de diversos problemas, tais como falta de água, saneamento, creche e a necessidade de mudança no modelo de assistência à saúde.

Esse cenário caracterizava a desigualdade de condições de vida de muitos brasileiros, o que implicava priorizar o atendimento à população, verificando aqueles em condições de maior risco e vulnerabilidade, de acordo com suas necessidades.

Nesse contexto, o Movimento da Reforma Sanitária Brasileira apontou algumas direções que sustentavam a formulação de um novo sistema de saúde. A primeira delas tinha a saúde como direito de todo cidadão, independentemente de o indivíduo ter contribuído para esse fim (alguma instituição previdenciária), sendo trabalhador rural ou não trabalhador. Em outras palavras, não se poderia excluir ou discriminar qualquer cidadão brasileiro do acesso à assistência pública de saúde. A segunda reconhecia que as ações de saúde deveriam garantir o acesso universal da população às ações de cunho preventivo e/ou curativo, até então separadas entre saúde e previdência, e, para tal, deveriam estar integradas em um único sistema. A terceira apontava a descentralização da gestão - tanto administrativa como financeira -, para estar mais próxima da população sob sua responsabilidade; e a quarta delegava ao controle social a prerrogativa de garantir, em qualidade e quantidade, as ações de saúde, em todos os seus níveis, para melhor atender aos problemas e às necessidades de saúde da população (PEPE, 2011).

Desse modo, buscou-se um caminho e uma estratégia para incorporar outros atores sociais, além do setor saúde, no processo de produção de saúde. Pautado no conceito ampliado de saúde, o MRSB expôs, no cenário político-sanitário, a importância do acesso às políticas públicas necessárias para se alcançar a qualidade de vida, manter, proteger ou 


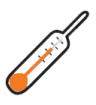

Outras conferências nacionais de saúde ocorreram antes e depois da $8^{\text {a }}$ CNS. Para conhecê-las, assista ao vídeo Saúde é democracia, disponível em: https://youtu.be/-_ HmqWCTEeQ.

restaurar a saúde. Esse aspecto é um entre outros que foram sendo incorporados ao relatório da $8^{\text {a }}$ Conferência Nacional de Saúde (CNS).

A 8 a Conferência Nacional de Saúde (CNS) foi um marco decisivo no processo de democratização da saúde. Realizada em 1986, caracterizou-se como um dos momentos mais importantes de luta pela universalização da saúde no Brasil e contou com a participação de diferentes atores sociais implicados na transformação dos serviços de saúde. Teve a participação de professores, profissionais da área de saúde, movimentos populares de saúde, sindicatos, e até grupos de pessoas não diretamente vinculados à saúde. O conjunto dessas forças impulsionou o Movimento da Reforma Sanitária Brasileira até a promulgação da Constituição Federal de 1988, na qual a

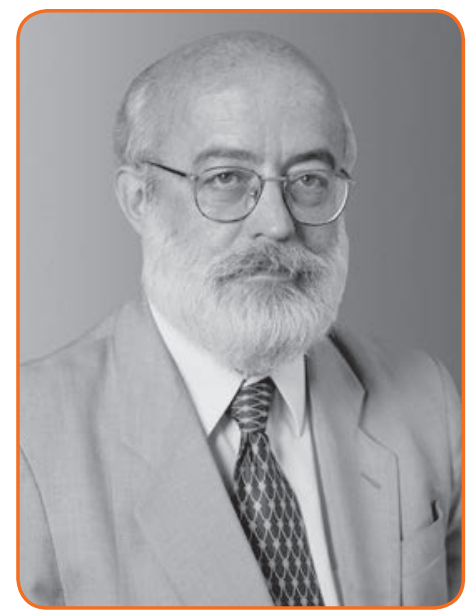

Sergio Arouca (1941-2003) foi um dos maiores expoentes da Reforma Sanitária Brasileira.

Fonte: Casa de Oswaldo Cruz. Reforma Sanitária Brasileira deixou forte marca no que se refere à saúde.

Antes da promulgação da Constituição, em 1988, instituiu-se como modelo de transição o Sistema Unificado e Descentralizado de Saúde (Suds), cujos objetivos eram:

* universalização e equidade no acesso aos serviços de saúde;

* integralidade dos cuidados assistenciais;

* descentralização das ações de saúde;

* implementação de distritos sanitários.

Foi um momento fundamental para o setor saúde, embora de curta duração, dado que, pela primeira vez, o governo federal repassou recursos para os estados e municípios efetuarem a expansão de suas redes de serviços, dando indícios da necessidade da municipalização que se consolidaria mais adiante, com o SUS. As secretarias estaduais de saúde tiveram um papel fundamental no Suds para a descentralização e aproximação com os municípios, os quais recebiam recursos financeiros federais, em consonância com uma programação de aproveitamento máximo da capacidade física instalada. Podemos afirmar que o Suds foi o antecedente mais imediato da criação do SUS.

Junto com o Suds e no bojo do movimento político “Diretas Já", o governo militar de transição instituiu uma Assembleia Nacional Constituinte, 
a qual ficou encarregada de elaborar uma nova Carta Magna para o país. No ano seguinte, foi promulgada a Constituição de 1988, como resposta à luta da sociedade brasileira por democracia e liberdade.

\section{O SUS e os modelos assistenciais em disputa no Brasil}

Como vimos, antes da criação do SUS, o Estado brasileiro não respondia às necessidades de saúde da população. O pensamento dominante era que o próprio indivíduo cuidasse de sua saúde. A ação estatal só ocorria em situações de gravidade, quando o indivíduo não podia resolver seu problema, ou em casos de epidemia que ameaçassem toda a população ou a economia.

Uma questão importante para compreensão das políticas de saúde e do próprio SUS, como política de Estado, é o entendimento de modelos de atenção (ou modelos assistenciais), que vão dar forma e conteúdo à organização dos serviços de saúde, com base em princípios e pressupostos orientadores das ações e do cuidado em saúde.

Os modelos assistenciais podem ser definidos como uma combinação de arranjos tecnológicos utilizados pela organização dos serviços de saúde em espaços e/ou populações. Incluem ações sobre o ambiente, grupos populacionais, equipamentos comunitários e usuários de serviços de saúde em diferentes níveis de complexidade (postos, centros de saúde, hospitais etc.), em função de problemas de saúde (danos e riscos) que compõem o perfil epidemiológico de uma dada população. Configuram-se, por um lado, como uma razão de ser, uma racionalidade, uma espécie de "lógica" que orienta a ação. De outro, como uma maneira de organizar os meios de trabalho (saberes e instrumentos) utilizados nas práticas ou nos processos de trabalho em saúde.

Até os anos 1980, havia um entendimento de que saúde era a ausência de doença, ou um completo bem-estar físico, mental e social.

Com a Constituição de 1988, o conceito de saúde mudou. Conforme apresentamos no capítulo anterior, ela passou a ser entendida como resultados de um conjunto de necessidades satisfeitas, intimamente ligadas à vida cotidiana das pessoas:

A saúde tem como fatores determinantes e condicionantes, entre outros, a alimentação, a moradia, o saneamento básico, o meio ambiente, o trabalho, a renda, a educação, o transporte, o lazer e o acesso aos bens e serviços essenciais; os níveis de saúde da população expressam a organização social e econômica do país.
Equipamentos comunitários podem ser equipamentos públicos de saúde, educação, cultura, lazer e similares. 
Diz respeito também à saúde as ações que se destinam a garantir às pessoas e à coletividade condições de bem-estar físico, mental e social (BRASIL, 1990b).

Corresponde, portanto, à dimensão técnica das práticas de saúde (PAIM, 2003)

No Brasil, por muito tempo, a população e as autoridades sanitárias percebiam a saúde como a ausência de doença. Com essa concepção, governos e autoridades de saúde consolidaram dois modelos principais de atenção à saúde (hegemônicos) para cuidar da população e para combater as doenças com campanhas, medicamentos e médicos: o modelo médico-assistencial e o modelo sanitarista-campanhista.

Os modelos assistenciais podem estar pautados na demanda espontânea (modelo médico hegemônico), nas necessidades de saúde (campanhas e programas especiais de saúde pública) ou, ainda, orientados por problemas (causas, riscos e danos) e necessidades em saúde. Sendo assim, atualmente se convive no Brasil, de forma contraditória ou complementar, com três modelos: o sanitarista-campanhista, o médico-assistencial privatista e o modelo de vigilância em saúde.

\section{Modelo sanitarista-campanhista}

No Brasil, as doenças mais relevantes no início do século passado foram as infecciosas. Para combatê-las, utilizou-se todo conhecimento tecnológico disponível à época, tais como as descobertas da bacteriologia e de medicamentos e vacinas para prevenir e tratar, com o objetivo de interromper o ciclo dessas doenças.

A estratégia organizada pelos médicos sanitaristas para chegar até os doentes, em diferentes regiões ou sob o risco de adoecimento, foram as campanhas, o que caracterizou, em nosso país, o modelo sanitarista-campanhista.

Esse modelo, institucionalizado no Brasil durante o século $\mathrm{XX}$, trata os problemas de saúde da população mediante campanhas (vacinação, combate às epidemias, reidratação oral etc.), de caráter temporário, e programas especiais (controle de tuberculose e da hanseníase, saúde da criança, saúde da mulher, saúde mental etc.). Tradicionalmente, essas formas de intervenção não contemplam a totalidade da situação de saúde, isto é, centram sua atenção no controle de agravos ou em 
alguns grupos supostamente em risco de adoecimento ou morte, sendo limitadas no que se refere ao conjunto de necessidades de saúde dos indivíduos.

Já os programas especiais possuem um conjunto de recursos (humanos, materiais e financeiros) e apresentam um caráter mais permanente do que as campanhas. Existem programas de controle de tuberculose ou de saúde da criança e da mulher que devem interagir com programas e campanhas de imunização e com as atividades da vigilância epidemiológica. Muitos programas substituíram campanhas que se prolongaram, enquanto outros constituem respostas pontuais a certas mudanças do perfil epidemiológico. O seu vínculo institucional tem origem basicamente no Ministério da Saúde, e eles são reproduzidos pelas secretarias estaduais e municipais de saúde.

\section{Modelo médico-assistencial privatista}

Ainda considerando saúde como ausência de doença, no governo Vargas (1930-1954), com a expansão da previdência social se fortaleceu o modelo médico-assistencial privatista, por meio dos IAPs que mencionamos anteriormente. Este modelo se originou na assistência filantrópica (Santas Casas de Misericórdia) e na medicina liberal (atendimento médico por consulta particular). Tal modelo de atenção à saúde é desenvolvido, predominantemente, por meio da assistência no hospital, pelo profissional médico e com uso de medicamentos. Por isso, é também conhecido como modelo de atenção medicalocêntrico ou hospitalocêntrico.

O modelo médico-assistencial privatista ainda é o mais difundido e predominante atualmente, apesar de não contemplar o conjunto dos problemas de saúde de toda a população, já que é baseado na demanda espontânea. Este modelo reforça a atitude dos indivíduos de só procurarem os serviços de saúde quando ficam doentes. É a pressão espontânea e desordenada da demanda que condiciona a organização de recursos para a oferta. Outras vezes, é a própria oferta, distorcida em relação às necessidades de saúde, que determina o consumo de serviços médicos e de saúde.

É um modelo presente na medicina liberal, nas cooperativas médicas, na medicina de grupo, no seguro-saúde (saúde suplementar privada) e, também, nos serviços públicos (hospitais, centros de saúde e laboratórios), quando não se encontram organizados para atender às necessidades de uma população definida. Predominantemente curativo, tende a prejudicar o atendimento integral ao paciente e à comunidade, além de não se comprometer com o impacto sobre o nível de saúde da população.
Os programas especiais e projetos de saúde serão abordados mais adiante, neste capítulo. 
As diferentes concepções de saúde foram apresentadas no Capítulo 1, "Um pouco de história: evolução das concepções de saúde, doença e cuidado". Já a discussão sobre vigilância em saúde será apresentada no próximo capítulo.

\section{Modelo de vigilância em saúde (Visau)}

O modelo de vigilância em saúde surge no bojo da crise do Sistema Nacional de Saúde brasileiro, nos anos 1970-1980, quando se observa o esgotamento dos modelos médico-assistencial privatista e sanitarista, já mencionados, em função das mudanças que vinham ocorrendo no perfil de adoecimento e morte da população. Essa formulação alternativa constitui-se, então, em um novo modelo de atenção que abrange duas dimensões: uma técnica, voltada para mudanças nas diretrizes e orientações do sistema, e outra gerencial, com foco no processo de trabalho e nas práticas de saúde.

Esse modelo tem como pressuposto a construção social de um novo sistema de saúde, entendido como processo de longo curso para o qual são necessárias mudanças político-ideológicas junto com mudanças cognitivo-tecnológicas. Também pressupõe uma nova concepção de saúde: trocar uma visão negativa da saúde, baseada na doença, por uma positiva, calcada na qualidade de vida. Para isso, seria necessário aceitar uma nova forma de pensar e fazer saúde (novo paradigma), superar as concepções biologicista, medicalizante, especializada e fragmentada do corpo humano e adotar outra, em que o nosso corpo é um todo, completo, e a saúde, uma produção social.

Nas décadas de 1970-1990, um conjunto de reflexões sobre promoção da saúde ganhou força no cenário internacional. Essas ideias se aproximam e reforçam a proposta do modelo de atenção à saúde denominado vigilância em saúde.

Um fato relevante ocorreu em 1974, quando o ministro da Saúde do Canadá, Marc Lalonde, apresentou um documento que se tornou referência para saúde de todo o mundo, denominado Relatório Lalonde, em que fazia a crítica aos sistemas de saúde estruturados sob a óptica biomédica. Nesse relatório, Lalonde propôs um novo conceito de saúde e afirmava que a determinação da saúde se encontrava fora do sistema de assistência à saúde, ou seja, estava baseada em quatro elementos gerais: a biologia, o ambiente, os estilos de vida e a organização sanitária. Com esse olhar sobre os determinantes de saúde, o relatório chamou a atenção para as desigualdades sociais.

Destacamos este relatório para que você compreenda que as modificações no conceito de saúde, que vivenciamos aqui no Brasil nas décadas de 1970 e 1980, estavam em consonância com o debate internacional sobre o tema. 


\section{O Sistema Único de Saúde}

As políticas de saúde adotadas no Brasil e os modelos assistenciais implementados no país demonstraram, claramente, a relação entre o entendimento de saúde e a proposta de governo para organização dos serviços ao longo do tempo. A identificação dessa relação nos permite, cidadãos e profissionais de saúde, compreender, na atualidade, como está organizada a saúde, suas ações, as políticas que a sustentam e os motivos que a levaram a se constituir como é hoje.

Com as questões apresentadas até aqui, você, profissional de saúde da rede de frio, pode refletir sobre qual sistema de saúde precisamos e sobre o que desejamos, compreender-se e situar-se como parte integrante e fundamental desse processo, na perspectiva de consolidar a implantação do SUS.

Uma das grandes conquistas do Movimento da Reforma Sanitária Brasileira foi conseguir, por suas lutas políticas, que a saúde fosse garantida, na Constituição Brasileira de 1988, como um direito de todos e um dever do Estado. E, ainda, que fosse instituído, em 1990, o Sistema Único de Saúde (SUS), seus princípios (universalidade, integralidade, equidade e participação social) e diretrizes (hierarquização e descentralização como norteadoras da gestão e organização do sistema e da rede de atenção à saúde).

O SUS nasceu com a perspectiva de mudar e alterar a situação de exclusão em que viviam os brasileiros, em especial aqueles que, por não contribuírem com a previdência social, não tinham o direito de ser atendidos em sua rede de hospitais.

Preconiza outra lógica de atenção à saúde, conforme expressa em seus princípios e diretrizes.

O arcabouço jurídico do SUS foi estabelecido na Constituição Federal de 1988, Título VIII (Da Ordem Social), Capítulo II (Da Seguridade Social), Seção II (Da Saúde), Artigo 196, definindo saúde como "um direito de todos e dever do Estado, garantido mediante políticas sociais e econômicas que visem à redução do risco de doença e de outros agravos, e ao acesso universal e igualitário às ações e serviços para sua promoção, proteção e recuperação" (BRASIL, 1988).

A regulamentação do sistema se efetivou com as Leis n. 8.080 e 8.142 de 1990. A Lei n. 8.080, chamada de Lei Orgânica da Saúde, regulamenta o texto constitucional, tratando da organização do SUS no que 


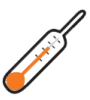

Como trabalhador do setor de saúde, é importante que você conheça as Leis n. 8.080 e 8.142, de 1990, disponíveis, respectivamente, em http:// www.planalto.gov.br/ccivil_03/ leis/L8080.htm e http://www. planalto.gov.br/ccivil_03/leis/ L8142.htm tange a seus princípios e diretrizes, condições para a promoção, proteção e recuperação da saúde, organização e funcionamento dos serviços correspondentes, entre outras providências. Em seu Título II (Do Sistema Único de Saúde), da Disposição Preliminar, Artigo 4, define que o SUS deve ser "o conjunto de ações e serviços de saúde, prestados por órgãos e instituições públicas federais, estaduais e municipais, da administração direta e indireta e das fundações mantidas pelo Poder Público" (BRASIL, 1990b).

A implantação do SUS, após sua definição na Constituição Federal e regulamentação nas leis orgânicas (Leis n. 8.080 e n. 8.142, de 1990), foi orientada pelas Normas Operacionais Básicas (NOBs) e portarias ministeriais. Tais normas estabeleceram as competências de cada esfera de governo e as condições para que estados e municípios assumissem suas novas atribuições.

A Lei n. 8.142/90 trata do controle social, complementando a Lei n. 8.080, e dispõe sobre a participação da comunidade na gestão do SUS, a ser efetivada por meio dos conselhos e das conferências de saúde, sendo, respectivamente, em cada esfera de governo, suas instâncias colegiadas. A lei também se refere às transferências intergovernamentais de recursos financeiros na área da saúde e estabelece regras para o financiamento do SUS, estabelecendo as obrigações dos três níveis de governo.

As NOBs e as Normas Operacionais da Assistência à Saúde (Noas) definiram critérios para que estados e municípios fossem habilitados a receber repasses de recursos do Fundo Nacional de Saúde (FNS) para seus fundos de saúde, operacionalizando a efetivação do SUS. Foram publicadas, a partir de 1991, quatro Normas Operacionais Básicas: NOB 01/91, NOB 01/92, NOB 01/93, NOB 01/96 e as Noas, 2001 e 2002. No Anexo A deste capítulo você encontrará um quadro sistematizando os quatros NOBs e duas Noas.

\section{Os pilares da organização do Sistema Único de Saúde}

O SUS se organiza por meio de princípios, diretrizes, normas operacionais e pactos. Esses elementos, juntos e em sinergia, possibilitam que o sistema siga direções e formatos organizacionais semelhantes, de modo a cumprir com os preceitos constitucionais no que tange ao acesso e à organização da rede de serviços de saúde.

Pressupõe comando único nas três esferas governamentais: no nível federal, o gestor é o ministro da saúde; no nível estadual, o secretário estadual da saúde; e no municipal, o secretário municipal da saúde. Desse 
modo, garante, ao mesmo tempo, a autonomia federativa, contribuindo para a articulação de ações entre os entes federados, e a especificidade no atendimento aos problemas e às necessidades de cada um deles.

\section{Princípios e diretrizes do SUS}

Dizem respeito aos eixos norteadores do sistema e às direções que devem conduzir a organização da rede de serviços de saúde, em todo território nacional, a fim de que os preceitos constitucionais sejam cumpridos. Os princípios dividem-se em finalísticos (ou doutrinários) e estratégicos (ou organizacionais).

Os princípios finalísticos dizem respeito à natureza do sistema que se pretende conformar. São eles:

* Universalidade - versa sobre o acesso aos serviços de saúde em todos os níveis de atenção, como garantia ao cuidado à saúde. O indivíduo passa, então, a ter direito de acesso a todos os serviços públicos de saúde, assim como àqueles contratados pelo poder público.

* Integralidade - concebida como um conjunto articulado de ações e serviços de saúde, preventivos e curativos, individuais e coletivos, que ocorrem nos diferentes níveis de complexidade do sistema. Ao ser constituído como ato em saúde, nas vivências cotidianas dos sujeitos nos serviços de saúde, produz transformações na vida das pessoas, cujas práticas eficazes de cuidado em saúde superam os modelos idealizados (PINHEIRO, 2009).

Equidade - significa assegurar ações e serviços de todos os níveis de atenção hierárquica, de acordo com as demandas exigidas pela população de determinada área. Assim, se a população de um bairro mais carente tem maior demanda por serviços de saúde do que a de um bairro de classe média alta, ela deve ter acesso a serviços que deem conta dessa necessidade. Portanto, deve-se garantir a todo cidadão o atendimento conforme suas necessidades, até o limite do que o sistema puder oferecer, sem privilégios e barreiras.

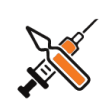

Lembre que, antes do SUS, somente quem contribuía para a previdência tinha direito ao atendimento de saúde.

Antes do SUS, havia forte hegemonia do modelo assistencial privatista, que centrava a atenção na demanda espontânea e na doença, e não na percepção de o sujeito como um ser integral, que deve ter sua saúde cuidada.

O modelo assistencial preconizado pelo SUS considera os sujeitos em seus contextos sociais, bem como os riscos e vulnerabilidades a que estão expostos. Esses conceitos serão detalhados no Capítulo 3, "Introdução à vigilância em saúde: vigilância epidemiológica, vigilância sanitária, ambiental e saúde do trabalhador". 
Equidade diz respeito à necessidade de se tratar desigualmente os desiguais "de forma a se alcançar a igualdade de oportunidades de sobrevivência, de desenvolvimento pessoal e social entre os membros de uma sociedade" (TEIXEIRA; PINTO; VILLASBOAS, 2004).

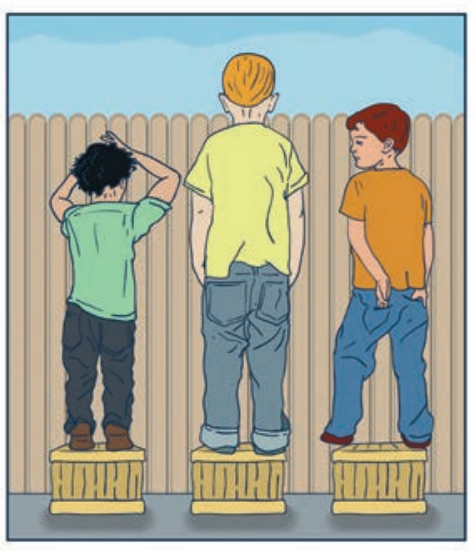

Igualdade

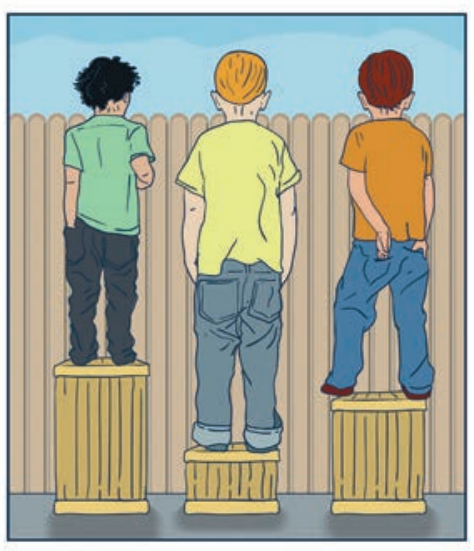

Equidade
A descentralização redefine responsabilidades e reforça a importância dos governos estaduais e municipais na condução da política de saúde. Envolve a transferência de poder decisório, da gestão de prestadores e de recursos financeiros, antes concentrados na esfera federal, para estados e, principalmente, para os municípios.
Os princípios estratégicos referem-se às diretrizes políticas, organizativas e operacionais, que indicam "como" deve vir a ser construído o SUS que se quer conformar, institucionalizar:

* Descentralização político-administrativa - com direção única em cada esfera de governo; envolvimento da União, dos estados, do Distrito Federal e dos municípios na prestação dos serviços de assistência à saúde da população, por meio da conjugação dos recursos financeiros, tecnológicos, materiais e humanos. O processo de descentralização teve como pressuposto fortalecer o papel dos municípios na oferta de atenção e cuidado, por estes estarem mais próximo dos seus cidadãos e dos problemas que os afligem em seu território.

* Regionalização - configura-se como um processo político, condicionado pelas relações estabelecidas entre diferentes atores sociais (governos, organizações, cidadãos) no espaço geográfico. Inclui, ainda, o desenvolvimento de estratégias e instrumentos de planejamento, integração, gestão, regulação e financiamento de uma rede de ações e serviços no território. Confere a ideia de tornar regional o que antes era centralizado nas grandes capitais, ou seja, levar um conjunto de unidades de saúde para perto das residências dos cidadãos ("interiorizando" os serviços de saúde em comunidades e cidades afastadas dos centros urbanos). Objetiva vincular o 
paciente à região para oferecer ações de promoção, prevenção e reabilitação, possibilitando maior resolutividade na prestação de serviços.

Como diretriz do SUS é eixo estruturante do Pacto de Gestão e deve orientar a descentralização de ações e serviços de saúde e dos processos de negociação e pactuação entre os gestores.

* Hierarquização - significa que os serviços devem ser organizados em níveis de complexidade tecnológica crescente (atenção primária, secundária e terciária), dispostos numa área geográfica delimitada e com a definição da população a ser atendida. Isso implica a capacidade de os serviços oferecerem, a uma determinada população, todas as modalidades de assistência, bem como o acesso a todo tipo de recurso tecnológico e graus de especialização disponíveis, possibilitando melhor resolubilidade. Desse modo, favorece o desenvolvimento das ações de vigilância epidemiológica, sanitária, controle de vetores, educação em saúde, além das ações de atenção ambulatorial e hospitalar, em todos os níveis de complexidade.

* Participação social - permite à população, por meio de suas entidades representativas (associação de usuários dos serviços de saúde, conselhos municipais e estaduais de saúde e conferências nacionais de saúde), participar do processo de formulação das políticas de saúde e do controle da sua execução, em todos os níveis, desde o local até o federal. A participação social (usuários) na gestão do SUS funciona pela ação democrática (voto) para criação de metas e planos de saúde de cada instância governamental. Os representantes comunitários têm poder de voto (de forma paritária, ou seja, 50\% dos votos) nas decisões a serem tomadas no âmbito da saúde, juntamente com gestores, prestadores de serviço e profissionais de saúde (os 50\% restantes dos votos).

\section{Para refletir}

Como trabalhador da rede de frio, você está inserido no Sistema Único de Saúde. Reflita um pouco e tente identificar os princípios do SUS na sua prática profissional. Quais desses princípios e diretrizes apresentados você consegue perceber?
Você verá mais sobre o Pacto de Gestão ainda neste capítulo e no Anexo B, ao final dele.

Resolubilidade é a exigência de que, quando um indivíduo busca o atendimento ou quando surge um problema de impacto coletivo sobre a saúde, o serviço correspondente esteja capacitado para enfrentá-lo e resolvê-lo até o nível da sua competência (BRASIL, 1990c). 
O Pacto pela Saúde define prioridades de atuação, articuladas e integradas, a partir de três outros pactos: Pacto pela Vida, Pacto em Defesa do SUS e Pacto de Gestão do SUS. Para saber um pouco mais sobre esses pactos, consulte o Anexo B deste capítulo.

\section{Os pactos do SUS}

A Portaria Ministerial n. 399/2006 (BRASIL, 2006b) estabelece o Pacto pela Saúde, que resulta em um conjunto de reformas institucionais do Sistema Único de Saúde nas três esferas de gestão do sistema, objetivando promover inovações nos processos e instrumentos de gestão para o alcance de maior eficiência e qualidade.

O Pacto pela Saúde, ao mesmo tempo, redefine as responsabilidades de cada gestor em função das necessidades de saúde da população e da equidade social. Sua implementação se dá pela adesão de municípios, estados e da União ao Termo de Compromisso de Gestão (TCG), que substitui os processos de habilitação das várias formas de gestão e estabelece metas e compromissos, renovados anualmente.

As formas de transferência dos recursos federais para estados e municípios também foram modificadas pelo Pacto pela Saúde, passando a ser integradas em grandes blocos de financiamento (Atenção básica; Atenção de média e alta complexidade ambulatorial e hospitalar; Vigilância em saúde; Assistência farmacêutica; Gestão do SUS; e Investimentos na rede de serviços de saúde), substituindo, assim, as muitas "caixinhas" que eram utilizadas para essa finalidade.

\section{Financiamento do Sistema Único de Saúde}

Trata da alocação de recursos do Fundo Nacional de Saúde, do repasse de forma regular e automática para estados, Distrito Federal e municípios. Para o recebimento desses recursos, os estados e municípios devem contar com:

* Fundo de Saúde;

橉Conselho de Saúde;

橉Plano de Saúde;

*⿻l木w Relários de Gestão;

* Contrapartida de Recursos para a Saúde no respectivo orçamento;

Comissão de Elaboração do Plano de Carreira, Cargos e Salário (PCCS).

O financiamento é feito pelas três esferas de governo, conforme determina a Constituição Federal de 1988, que estabelece as fontes de receita para custear as despesas com ações e serviços públicos de saúde.

Os recursos federais destinados a ações e serviços de saúde passaram a ser organizados e transferidos na forma de seis blocos de financiamento: 


\section{Atenção básica;}

2.Atenção de média e alta complexidade ambulatorial e hospitalar;

3. Vigilância em saúde;

4. Assistência farmacêutica;

5. Gestão do SUS;

6. Investimentos na rede de serviços de saúde.

No bloco de financiamento da vigilância em saúde, estão definidas as ações de vigilância, proteção e promoção da saúde, nas quais se incluem o controle de doenças e a produção de insumos, entre eles os imunobiológicos definidos pelo Programa Nacional de Imunizações.

A Portaria Ministerial n. 1.378, de junho de 2013, regulamenta as responsabilidades e define diretrizes para execução e financiamento das ações de vigilância em saúde pela União, estados, Distrito Federal e municípios, relativos ao Sistema Nacional de Vigilância em Saúde e Sistema Nacional de Vigilância Sanitária (BRASIL, 2013).

Os blocos de financiamento são constituídos por componentes, de acordo com as especificidades de suas ações e os serviços de saúde pactuados. Os recursos federais, que compõem cada bloco de financiamento, são transferidos aos estados, Distrito Federal e municípios, fundo a fundo, em conta única e específica para cada bloco de financiamento, observados os atos normativos específicos.

\section{Organização dos serviços de saúde}

A organização da rede de saúde do SUS (no Título II do Sistema Único de Saúde e na disposição preliminar Art. $4^{\circ}$ ) está descrita como o conjunto de ações e serviços prestados por órgãos e instituições públicas federais, estaduais e municipais, da administração direta e indireta e das fundações mantidas pelo Poder Público. Ainda estão incluídas as instituições públicas federais, estaduais e municipais de controle de qualidade, pesquisa e produção de insumos, de medicamentos, inclusive de sangue e hemoderivados, e de equipamentos para saúde. Ressalva que é permitido à iniciativa privada participar do sistema, em caráter complementar e sob o controle social.

Historicamente, os serviços de saúde se organizam de formas diversas para atender aos modelos de atenção vigentes (Figura 1). Na organização do SUS destacam-se:

* a forma piramidal, de base larga, onde se organiza hierarquicamente um conjunto de serviços e unidades de saúde: o nível primário 
dos cuidados (postos e centro de saúde e saúde da família); mais ao meio, o nível secundário (especialidades médicas e pequenos hospitais local e regional); e no topo, o nível terciário (hospitais de referência);

* multicêntrica, com um conjunto de unidades de saúde organizadas em círculos concêntricos e com complexidades diversas de atenção;

* a forma em rede, organizações poliárquicas de conjuntos de serviços de saúde, vinculados entre si por uma missão única, por objetivos comuns e por uma ação cooperativa e interdependente, que permitem ofertar uma atenção contínua e integral a determinada população, coordenada pela atenção primária à saúde (MENDES, 2011).

Figura 1 - Exemplos de organização dos serviços de saúde

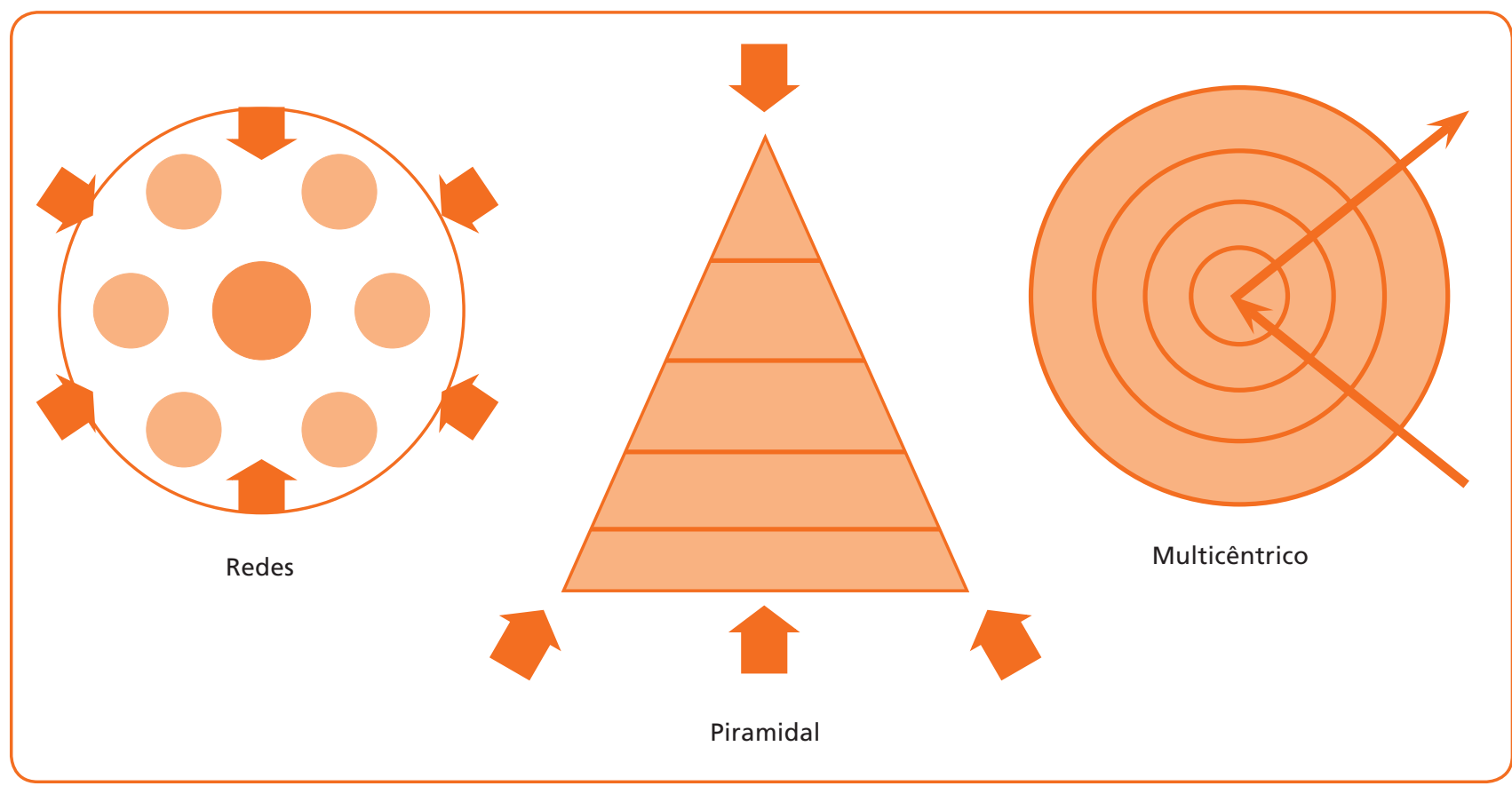

Fonte: Elaboração de Grácia Maria de Miranda Gondim.

Embora sejam inegáveis os avanços alcançados pelo SUS nos últimos 26 anos, são evidentes as dificuldades para se superar a forte fragmentação das ações e dos serviços de saúde e qualificar a gestão do cuidado, no contexto atual.

A realidade geográfica brasileira se caracteriza por um conjunto diversificado de contextos regionais e fortes diferenças socioeconômicas, que acarretam necessidades de saúde diferentes entre as regiões. O quadro se aprofunda pelo alto peso da oferta de serviços privados, pelas pressões sobre o mercado na área da saúde e pelo desafio de conviver com a 
complexa inter-relação entre acesso, escala, escopo, qualidade e custo-efetividade. Tais fatos demonstram a complexidade do processo de constituição de um sistema unificado e integrado no Brasil (BRASIL, 2014).

O que se propõe, hoje, para resolver o cenário exposto é inovar na organização do sistema de saúde, redirecionando suas ações e serviços na perspectiva de se criar a Rede de Atenção à Saúde (RAS), de modo a propiciar impacto positivo nos indicadores de saúde das diferentes populações.

\section{Redes de Atenção à Saúde}

São arranjos organizativos de ações e serviços de saúde, com diferentes densidades tecnológicas, articulados por meio de sistemas de apoio técnico, logístico e de gestão, para garantir a integralidade do cuidado.

Seu objetivo é promover a integração sistemática de ações e serviços de saúde com atenção contínua, integral, de qualidade, responsável e humanizada, como forma de melhorar o desempenho do SUS, no que tange ao acesso, à equidade, à eficácia clínica e sanitária e à eficiência econômica (MENDES, 2011).

Experiências recentes com RAS têm demonstrado sua eficiência e eficácia na oferta de serviços de saúde, por ter na atenção primária ou atenção básica a coordenação do cuidado e ordenação da rede. Isso possibilita criar mecanismos para superar a fragmentação, tanto em termos de organização interna (alocação de recursos, coordenação clínica etc.), quanto de sua capacidade para fazer face aos atuais desafios do cenário socioeconômico, demográfico, epidemiológico e sanitário (BRASIL, 2014).

As características da RAS apontam para a formação de relações horizontais entre os pontos de atenção e o centro de comunicação na Atenção Básica à Saúde (ABS), em função:

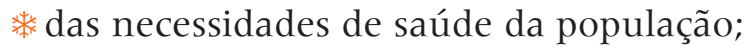

* da responsabilização na atenção contínua e integral;

do cuidado multiprofissional;

do compartilhamento de objetivos e compromissos com os resultados sanitários e econômicos.
Pontos de atenção à saúde são espaços onde se ofertam determinados serviços de saúde, por exemplo, os domicílios, as unidades básicas de saúde, as unidades ambulatoriais especializadas, os serviços de hemoterapia e hematologia, os centros de apoio psicossocial, as residências terapêuticas, entre outros. Os hospitais podem ter vários pontos de atenção à saúde: o ambulatório de prontoatendimento, a unidade de cirurgia ambulatorial, o centro cirúrgico, a maternidade, a unidade de terapia intensiva, a unidade de hospital/ dia, entre outros (MENDES, 2011). 


\section{A atenção básica e o SUS}

O Sistema Único de Saúde compreende ações que vão desde o nível primário, de caráter mais preventivo, até o terciário, de caráter mais reabilitador. O nível primário equivale à atenção básica em saúde, que é caracterizada pelo Ministério da Saúde como:

[...] um conjunto de ações de saúde, no âmbito individual e coletivo, que abrange a promoção e a proteção da saúde, a prevenção de agravos, o diagnóstico, o tratamento, a reabilitação, a redução de danos e a manutenção da saúde com o objetivo de desenvolver uma atenção integral que impacte na situação de saúde e autonomia das pessoas e nos determinantes e condicionantes de saúde das coletividades (BRASIL, 2012, p.19).

Para ver um resumo das diretrizes da atenção básica, consulte o Anexo $C$ deste capítulo. Para conhecer a política na íntegra, visite o endereço http://189.28.128.100/dab/docs/ publicacoes/geral/pnab.pdf

A atenção básica é a expressão intensa de alguns princípios do SUS, como universalidade, integralidade do cuidado, descentralização, regionalização, equidade e participação social. Possui algumas diretrizes para o desenvolvimento das ações, que estão registradas na Política Nacional de Atenção Básica (BRASIL, 2012).

A atenção básica no Brasil vem se desenvolvendo, prioritariamente, por meio da Estratégia de Saúde da Família (ESF). A qualificação da ESF e de outras estratégias de organização da atenção básica deverão seguir as diretrizes da atenção básica e do SUS, configurando um processo progressivo e singular que considera e inclui as especificidades locorregionais.

O trabalho realizado pelos profissionais da rede frio de imunobiológicos é fundamental para a atenção básica e para as ações de vigilância e proteção da saúde. Por isso, independentemente de onde o trabalhador se situe no sistema, no nível central, nos estados e municípios ou na Atenção Básica/ESF, suas ações (desde estoque, preparação e distribuição de imunobiológico, manutenção de equipamentos até a sala de vacinação na unidade de saúde) são estratégicas para a diminuição de agravos e mortes na população, em especial os relacionados às doenças preveníveis por imunização.

\section{A promoção da saúde e o SUS}

A promoção da saúde é um elemento importante na mudança de modelo de atenção à saúde proposta pelo SUS. Ela é entendida como um mecanismo para fortalecer e implantar uma política transversal, integrada e intersetorial, que possibilite o diálogo entre as diversas áreas do setor sanitário, outros setores do governo, setor privado e não 
governamental e a sociedade. Esse diálogo visa criar redes de compromisso e corresponsabilidade voltadas para a qualidade de vida da população, em que todos são partícipes na proteção e no cuidado com a vida. Uma política que se realiza na articulação sujeito/coletivo, público/privado, Estado/sociedade, clínica/política, setor sanitário/outros setores, visando romper a excessiva fragmentação na abordagem do processo saúde-adoecimento e reduzir a vulnerabilidade, os riscos e os danos que nele se produzem (BRASIL, 2006, p.16).

A Política Nacional de Promoção da Saúde (PNPS), proposta pelo Ministério da Saúde em 2006, tem como objetivo promover a qualidade de vida e reduzir vulnerabilidade e riscos à saúde, relacionados aos seus determinantes e condicionantes - modos de viver, condições de trabalho, habitação, ambiente, educação, lazer, cultura, acesso a bens e serviços essenciais. Suas diretrizes são:

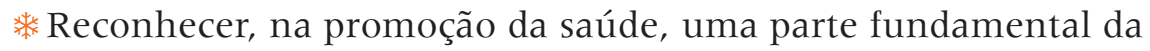
busca da equidade, da melhoria da qualidade de vida e de saúde.

* Estimular as ações intersetoriais, buscando parcerias que propiciem o desenvolvimento integral das ações de promoção da saúde.

* Fortalecer a participação social como fundamental na consecução de resultados de promoção da saúde, em especial a equidade e o empoderamento individual e comunitário.

* Promover mudanças na cultura organizacional, com o objetivo de implementar a adoção de práticas horizontais de gestão e estabelecimento de redes de cooperação intersetoriais.

* Incentivar a pesquisa em promoção da saúde, avaliando eficiência, eficácia, efetividade e segurança das ações prestadas.

Divulgar e informar aos profissionais de saúde, gestores e usuários do SUS sobre iniciativas voltadas à promoção da saúde, considerando metodologias participativas e o saber popular e tradicional.

Embora as ações dos profissionais da rede frio de imunobiológicos sejam voltadas para a proteção da população, elas também se inserem no campo da promoção da saúde na medida em que orientam a população quanto ao uso dos imunobiológicos - o calendário, as campanhas e os esclarecimentos quanto ao manuseio e ao uso desses insumos.
A PNPS tem como base as definições constitucionais, a legislação que regulamenta o SUS, as deliberações das conferências nacionais de saúde e o Plano Nacional de Saúde (2004/2007).

Representa um esforço para o enfrentamento dos desafios de produção da saúde em um cenário sócio-histórico cada vez mais complexo, que exige a reflexão e a qualificação contínuas das práticas sanitárias e do sistema de saúde. 


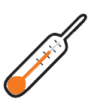

Os programas e projetos destinados a fortalecer o SUS estão disponíveis no portal do Ministério da Saúde. Acesse $<$ http://portalsaude.saude.gov br/> e confirme as iniciativas já propostas para que tenhamos o SUS que queremos e a atenção à saúde da população desejada por todos.

\section{Os programas e projetos de saúde}

Os programas e projetos de saúde são estratégias de ação organizadas para atingir alguns objetivos do SUS, no que tange a:

*⿻enças e agravos de longa permanência na população (endêmicos)

- hanseníase, tuberculose, malária, dengue, doença de Chagas, entre outras;

*⿻ent doencas e agravos emergentes - diabetes, hipertensão, Aids, violência, acidentes de trânsito de grande magnitude na população;

* grupos sociais vulneráveis - crianças, mulheres, idosos, indígenas, quilombolas, ribeirinhos, outros;

* melhoria da atenção - agentes comunitários, Estratégia de Saúde da Família; Saúde do Idoso e Envelhecimento; Projeto Terapêutico Singular (PTS); Projeto de Saúde no Território (PST); Programa Nacional de Imunizações (PNI).

\section{Programa Nacional de Imunizações}

A história da política de imunizações no país é muito recente, tendo como marco o término da campanha de erradicação da varíola, iniciada em 1962, e a criação, em 1973, do Programa Nacional de Imunizações (PNI). Criado no âmbito do processo de formulação de grandes programas nacionais, foi lançado oficialmente em Brasília com a presença de personalidades destacadas nas áreas de saúde pública e de controle de doenças. Vinculava-se funcionalmente à Divisão Nacional de Epidemiologia e Estatística de Saúde (DNEES) (ASSOCIAÇÃO DOS MÉDICOS SANITARISTAS DE SÃO PAULO, 1980).

No documento que consubstancia conceitualmente o PNI, são citadas exigências programáticas, tais como (BENCHIMOL, 2001, p. 320):

* necessidade de se estender as vacinações às áreas rurais;

* aperfeiçoar a vigilância epidemiológica em todo o território nacional;

* capacitar laboratórios oficiais para respaldarem com diagnóstico;

* instituir pelo menos um laboratório nacional de referência para o controle de qualidade das vacinas;

* racionalizar sua aquisição e distribuição;

燐 uniformizar as técnicas de administração;

* promover a educação em saúde para aumentar a receptividade da população aos programas de vacinação. 
No processo de criação do programa havia uma instância chamada Central de Medicamentos (Ceme), cujo papel foi estratégico na concepção do PNI, pois, como órgão responsável pela aquisição e pelo suprimento de vacinas para o Ministério da Saúde, identificava a necessidade de um planejamento integrado das demandas nacionais de imunobiológicos. Isso deu uma nova dimensão à questão dos imunobiológicos no país, nos aspectos de gerência, planejamento, suprimento e controle de qualidade (TEMPORÃO, 2003).

Em 1975, foi promulgada a Lei n. 6.259, que dispõe sobre a organização das ações de vigilância epidemiológica, de notificação compulsória de doenças e da regulamentação do PNI. Essa lei torna obrigatória a vacinação básica no primeiro ano de vida, submetendo os pais infratores à suspensão do pagamento do salário-família. Instituía, também, a notificação compulsória de um conjunto de doenças selecionadas (TEMPORÃO, 2003).

O objetivo principal do PNI foi oferecer vacinas com qualidade a todas as crianças que nascem no país, buscando alcançar coberturas vacinais de $100 \%$, de forma homogênea em todos os municípios e bairros, e, também, erradicar, eliminar e controlar as doenças imunopreveníveis na população.

De acordo com o Manual de Procedimentos para Vacinação (FUNDAÇÃO NACIONAL DE SAÚDE, 2001), são objetivos do PNI, ainda, contribuir para:

- a manutenção do estado de erradicação da poliomielite;

- o controle ou a erradicação do sarampo, da difteria, do tétano neonatal e acidental, da coqueluche, das formas graves da tuberculose, da rubéola, da caxumba, da hepatite $B$, da febre amarela, da raiva, das doenças invasivas causadas por Haemophilus influenzae tipo B e da poliomielite;

- o controle de outros agravos, coordenando o suprimento e a administração de imunobiológicos indicados para situações ou grupos populacionais específicos, tais como: vacina contra a meningite meningocócica tipo $C$, vacina contra a febre tifoide, vacina contra a hepatite $A$, vacina acelular contra a difteria, o tétano e a coqueluche.

O PNI é responsável pela normatização técnica das vacinas, do calendário de vacinação, bem como dos procedimentos e indicações especiais. Define suas estratégias e ações (nacionais e regionais), tomando como base estudos científicos e a epidemiologia das doenças imunopreveníveis. Possui uma logística estruturada para aquisição, armazenamento e distribuição dos imunobiológicos às Secretarias estaduais de Saúde,
O PNI será apresentado em outros capítulos deste livro. Neste capítulo, tratamos o PNI como programa do SUS em prol da melhoria da atenção à saúde da população. No Capítulo 3, ele será mencionado no âmbito da vigilância em saúde. E no Capítulo 8 do livro Rede de Frio: gestão, especificidades e atividades (SILVA; FLAUZINO, 2016), como normatizador das ações da rede de frio de imunobiológicos. 
A interdisciplinaridade é uma das ferramentas de trabalho dos profissionais do SUS, pois possibilita compreender e integrar os diferentes processos de trabalho, na perspectiva de tratar o sujeito como um ser complexo e integral, e não fragmentado em partes, em que cada profissional é responsável por uma ação específica. garantindo, assim, a chegada destes ao destino final - os municípios e cada sala de vacinação.

\section{Considerações finais}

O processo de trabalho em saúde originou-se do modelo fordista (de Henry Ford), do trabalho em escala, pensando que cada profissional seria responsável por uma parte do corpo do paciente, fragmentando e segmentando o entendimento do corpo humano. Observou-se, em seguida, que a melhor forma de entender o paciente seria segundo a visão holística, integral, em que o paciente é considerado um todo social. Não é à toa que um dos princípios do SUS seja a integralidade.

Quando trabalhamos com a concepção do processo saúde-doença, a complexidade dos sujeitos e de suas relações sociais e pessoais demanda um conjunto de cuidados que envolve, de forma interdisciplinar, todos os trabalhadores das redes - de atenção, de vigilância e de promoção da saúde, todos fundamentais e indispensáveis.

O trabalho na rede de frio de imunobiológicos é complexo, com muitas funções e postos de trabalho, os quais quase não se intercomunicam, trazendo para o conjunto dos trabalhadores os desafios da necessidade de articulação e diálogo para realização de suas atividades.

Para desenvolver estratégias de superação desses desafios, é fundamental que todos os profissionais de saúde, em especial, aqueles da rede de frio de imunobiológicos, conheçam um pouco das políticas de saúde, da constituição do Sistema Único de Saúde, de sua organização e seus programas e projetos. É conhecendo esse processo histórico e percebendo sua identidade e responsabilidade nele que os profissionais da rede de frio poderão criar formas para melhor desenvolver suas ações, visando contribuir para a proteção da saúde e a prevenção de doenças por meio dos imunobiológicos.

\section{Referências}

ASSOCIAÇÃO DOS MÉDICOS SANITARISTAS DE SÃO PAULO. A nova política do Ministério: campanhas substituem programas de vacinação. Boletim Informativo, São Paulo, v. 4, n. 4, abr. 1980.

BENCHIMOL, J. L. (Org.). Febre amarela: a doença e a vacina, uma história inacabada. Rio de Janeiro: Ed. Fiocruz, 2001.

BERTOLLI FILHO, C. História da saúde pública no Brasil: (livro do professor). Rio de Janeiro: Ática, 1996. 
BRASIL. Lei n. 8.080, de 19 de setembro de 1990. Dispõe sobre as condições para a promoção, proteção e recuperação da saúde, a organização e o funcionamento dos serviços correspondentes e dá outras providências. Diário Oficial da União, Brasília, DF, 20 set. 1990 b.

BRASIL. Lei n. 8.142, de 28 de dezembro de 1990. Dispõe sobre a participação da comunidade na gestão do Sistema Único de Saúde - SUS e sobre as transferências intergovernamentais de recursos financeiros na área da saúde e dá outras providências. Diário Oficial da União, Brasília, DF, p. 25694, 31 dez. 1990.

BRASIL. Ministério da Previdência Social. A Instituição. Brasília, DF, 2007. Disponível em: <http:// www1.previdencia.gov.br/aeps2007/16_01_01_01.asp>. Acesso em: 19 jul. 2016.

BRASIL. Ministério da Saúde. Diretrizes operacionais para os Pactos pela Vida, em defesa do SUS e de Gestão. Brasília, DF, 2006a. Disponível em: <http://dtr2001.saude.gov.br/editora/produtos/livros/ pdf/06_0257_M.pdf>. Acesso em: 25 jan. 2014.

BRASIL. Ministério da Saúde. Financiamento do SUS. Brasília, DF, 2013. Disponível em: <http://portalsaude.saude.gov.br/index.php/o-inisterio/principal/siops/mais-sobre-siops/5976financiamento-do-sus>. Acesso em: 18 jan. 2014.

BRASIL. Ministério da Saúde. Portaria n. 399, de 22 de fevereiro de 2006. Divulga o Pacto pela Saúde 2006 - Consolidação do SUS e aprova as diretrizes operacionais do referido Pacto. Diário Oficial da União, Brasília, DF, 23 fev. 2006. Seção 1, p. 43.

BRASIL. Ministério da Saúde. Portaria n. 1.378, de 9 de julho de 2013. Regulamenta as responsabilidades e define diretrizes para execução e financiamento das ações de Vigilância em Saúde pela União, Estados, Distrito Federal e Municípios, relativos ao Sistema Nacional de Vigilância em Saúde e Sistema Nacional de Vigilância Sanitária. Diário Oficial da União, Brasília, DF, 10 jul. 2013. Seção 1, p. 48.

BRASIL. Ministério da Saúde. Portaria n. 2.488, de 21 de outubro de 2011. Aprova a Política Nacional de Atenção Básica, estabelecendo e revisão de diretrizes e normas para a organização da Atenção Básica, para a estratégia Saúde da Família (ESF) e o Programa de Agentes Comunitários de Saúde (Pacs). Diário Oficial da União, Brasília, DF, 24 out. 2011. Seção 1, p. 48.

BRASIL. Ministério da Saúde. Departamento de Atenção Básica. Financiamento da atenção básica. Brasília, DF, [2014?]. Disponível em: <http://dab.saude.gov.br/portaldab/financiamento.php>. Acesso em: 18 jan. 2014.

BRASIL. Ministério da Saúde. Departamento de Atenção Básica. Política Nacional de Atenção Básica. Brasília, DF, 2012. Disponível em: <http://189.28.128.100/dab/docs/publicacoes/geral/pnab. pdf>. Acesso em: 18 jul. 2016.

BRASIL. Ministério da Saúde. Departamento de Atenção Básica. Saúde mais perto de você. Brasília, DF, [2014?]. Disponível em: <http://dab.saude.gov.br/serie_pactos.php>. Acesso em: 25 jan. 2014.

BRASIL. Ministério da Saúde. Secretaria de Atenção à Saúde. Implantação das Redes de Atenção à Saúde e outras estratégias da SAS. Brasília, DF, 2014.

BRASIL. Ministério da Saúde. Secretaria de Vigilância Sanitária. Política Nacional de Promoção da Saúde. Brasília, DF, 2006b. Disponível: <http://bvsms.saude.gov.br/bvs/publicacoes/politica_ promocao_saude.pdf>. Acesso em: 18 jul. 2016. 
BRASIL. Ministério da Saúde. Secretaria Nacional de Assistência à Saúde. ABC do SUS: doutrina e princípios. Brasília, DF, 1990c. Disponível em: <http://biblioteca.planejamento.gov.br/bibliotecatematica-1/textos/saude-epidemias-xcampanhas-dados-descobertas/texto-17-abc-do-sus-doutrinase-principios.pdf>. Acesso em: 10 jan. 2014

BRASIL. Ministério da Saúde. Subsecretaria de Planejamento e Orçamento. Plano Nacional de Saúde: PNS, 2012-2015. Brasília, DF, 2011. Disponível em: <conselho.saude.gov.br/biblioteca/ Relatorios/plano_nacional_saude_2012_2015.pdf> . Acesso em: 18 jan 2014.

CEFOR. Breve história das políticas de saúde no Brasil. São Paulo, [199-]. Mimeografado.

CENTRO NACIONAL DE EPIDEMIOLOGIA (Brasil). Retrospectiva das ações do Programa Nacional de Imunizações-PNI. Brasília, DF: Ministério da Saúde, 2001.

CONSELHO NACIONAL DE SECRETÁRIOS DE SAÚDE (Brasil). Gestão do trabalho na saúde. Brasília, DF, 2007.

FIOCRUZ. Canal Saúde. Histórico da Conferência Nacional de Saúde. Rio de Janeiro, 2011. 1 vídeo. Disponível em: <http://www.canal.fiocruz.br/video/index.php?v=historico-das-conferencia-nacional-desaude>. Acesso em: 11 jan. 2014.

FUNDAÇÃO NACIONAL DE SAÚDE (Brasil). Manual de procedimentos para vacinação. 4. ed. rev. atual. e ampl. Brasilia, DF, 2001.

FUNDO NACIONAL DE SAÚDE (Brasil). Definição de blocos. Brasília, DF, 21 jul. 2016. Disponível em: <http://www.fns.saude.gov.br/visao/carregarMenu.jsf?coMenu=17>. Acesso em: 18 jan. 2014.

GONDIM, G. M. M. Territórios da atenção básica: múltiplos, singulares ou inexistentes? 2011. Tese (Doutorado) - Escola Nacional de Saúde Pública Sergio Arouca, Rio de Janeiro, 2011.

GONDIM, G. M. M.; MONKEN, M. Territorialização em saúde. In: PEREIRA, I. B.; LIMA, J. C. F. (Org.). Dicionário de educação profissional em saúde. 2. ed. ampl. e rev. Rio de Janeiro: Escola Politécnica de Saúde Joaquim Venâncio/Fiocruz, 2008. p. 392-398.

GUIMARÃES, R. (Org.). Saúde e medicina no Brasil: contribuição para o debate. Rio de Janeiro: Graal, 1984.

MENDES, E.V. As redes de atenção à saúde. Brasília, DF: Organização Pan-Americana da Saúde, 2011.

OLIVEIRA, M. A importância da ação interdisciplinar no serviço de saúde. Boletim Epidemiológico Paulista, São Paulo, v. 4, n. 38, p. 19, fev. 2007. Disponível em: <http://periodicos.ses.sp.bvs.br/pdf/ bepa/v4n38/v4n38a05.pdf>. Acesso em: 31 jan. 2014.

PAIM, Jairnilson Silva. Modelos de atenção e vigilância da saúde. In: ROUQUAYROL, M. Z.; ALMEIDA FILHO, N. Epidemiologia \& saúde. 6. ed. Rio de Janeiro: MEDSI, 2003. p. 567-571.

PEPE, Vera Lúcia Edais; VENTURA, Míriam (Coord.). Assistência farmacêutica em foco no Estado do Rio de Janeiro: normas e documentação para ação. 2. ed. rev. e atual. Rio de Janeiro: Fiocruz/Escola Nacional de Saúde Pública: Fundação Carlos Chagas Filho de Amparo à Pesquisa do Estado do Rio de Janeiro, 2011. 
PINHEIRO, R. Integralidade. In: PEREIRA, I. B.; LIMA, J. C. F. (Org.). Dicionário de educação profissional em saúde. 2. ed. ampl. e rev. Rio de Janeiro: Escola Politécnica de Saúde Joaquim Venâncio/Fiocruz, 2009.

POSSAS, Cristina A. Saúde e trabalho: a crise da previdência social. Rio de Janeiro: Graal, 1981.

RONCALLI, A. G. O desenvolvimento das políticas públicas de saúde no Brasil e a construção do Sistema Único de Saúde. In: PEREIRA, Antonio Carlos (Org.). Odontologia em saúde coletiva: planejando ações e promovendo saúde. Porto Alegre: Artmed, 2003. cap. 2, p. 28-49.

SILVA, L. J. Revista de Saúde Pública: 30 anos de evolução. Revista de Saúde Pública, São Paulo, v. 30, n. 6, p. 503-505, 1996.

SILVA, M. N.; FLAUZINO, R. F. (Org.). Rede de frio: gestão, especificidades e atividades. Rio de Janeiro: Ed. Fiocruz, 2016. No prelo.

TEIXEIRA, Carmen Fontes. SUS e a Vigilância da Saúde. Rio de Janeiro: Escola Politécnica de Saúde Joaquim Venâncio/Fiocruz, 2001.

TEIXEIRA, Carmen Fontes; PINTO, L. L.; VILLASBÔAS, A. L. O processo de trabalho da vigilância em saúde. Rio de Janeiro: Escola Politécnica de Saúde Joaquim Venâncio/Fiocruz, 2004. v. 5.

TEMPORÃO, J. G. O Programa Nacional de Imunizações (PNI): origens e desenvolvimento. História, Ciências, Saúde Manguinhos, v. 10, p. 601-617, 2003. Suplemento 2. 


\section{Anexo A - Sistematização resumida das ideias tratadas nas NOBs e Noas}

\begin{tabular}{|c|c|}
\hline $\begin{array}{l}\text { NOB 01/91 } \\
\text { e 01/92, } \\
\text { atualizadas } \\
\text { pela } 01 / 93\end{array}$ & $\begin{array}{l}\text { Apresentam como ideias centrais: } \\
\text { - a definição do processo de descentralização, colocando o município como } \\
\text { gestor; } \\
\text { - a criação das formas de gestão; e } \\
\text { - a definição dos requisitos e responsabilidade para habilitação em alguma } \\
\text { forma de gestão (incipiente, parcial ou semiplena). }\end{array}$ \\
\hline NOB 01/96 & $\begin{array}{l}\text { Apresenta, resumidamente: } \\
\text { - a criação das instâncias de articulação intergestores - Comissões Intergestoras } \\
\text { Bipartite (CIB, reunindo município e estado) e Comissões Intergestoras } \\
\text { Tripartite (CIT, reunindo município, estado e federação); } \\
\text { - a redefinição do papel dos gestores nas esferas estadual e federal; } \\
\text { - a definição das realizações entre os sistemas municipais de saúde; } \\
\text { - a redefinição sobre as condições de gestão de estados e municípios (da } \\
\text { Atenção Básica e do sistema municipal); } \\
\text { - as bases para implantação de um novo modelo de atenção à saúde; } \\
\text { reorganização do modelo de atenção e da gestão do SUS e de alocação dos } \\
\text { recursos; } \\
\text { - a definição das responsabilidades e fontes de financiamento e suas } \\
\text { modalidades; }\end{array}$ \\
\hline Noas 2001 & $\begin{array}{l}\text { Aumenta as responsabilidades dos municípios na Atenção Básica: } \\
\text { - definindo o processo de regionalização da assistência; } \\
\text { - criando mecanismos para o fortalecimento da capacidade de gestão do SUS; e } \\
\text { - procedendo à atualização dos critérios de habilitação de estados e municípios. }\end{array}$ \\
\hline Noas 2002 & $\begin{array}{l}\text { Estabelece a regionalização como estratégia de hierarquização dos serviços de } \\
\text { saúde e de maior equidade. }\end{array}$ \\
\hline
\end{tabular}




\section{Anexo B - Sobre os pactos que compõem o Pacto pela Saúde}

O Pacto pela Vida é o compromisso entre os gestores do SUS em torno de metas prioritárias que impactam a situação de saúde da população brasileira. São seis as prioridades pactuadas:

saúde do idoso;

*âncer de colo de útero e de mama;

mortalidade materno-infantil;

* doenças emergentes e endemias, com ênfase na dengue, hanseníase, tuberculose, malária e influenza;

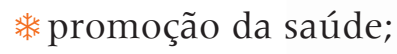

* atenção básica à saúde.

O Pacto em Defesa do SUS envolve ações concretas e articuladas nas instâncias municipal, estadual e federal, reforçando o SUS como política de Estado e defendendo seus princípios básicos, presentes na Constituição Federal. Reforça a dimensão política da saúde, utilizando como estratégia a mobilização social como direito de cidadania e tendo o financiamento público da saúde como um dos pontos principais. As prioridades do Pacto em Defesa do SUS são:

* implementar um projeto permanente de mobilização social para garantir, a longo prazo, o aumento dos recursos orçamentários e financeiros para a saúde;

* aprovar o orçamento do SUS nas três esferas de gestão, enfatizando os deveres dessas esferas na garantia de cuidado à população;

* elaborar e divulgar a carta dos direitos dos usuários do SUS.

A carta dos direitos dos usuários do SUS, em sua apresentação, diz:

A carta que você tem nas mãos baseia-se em seis princípios básicos de cidadania. Juntos, eles asseguram ao cidadão o direito básico ao ingresso digno nos sistemas de saúde, sejam eles públicos ou privados. A carta é também uma importante ferramenta para que você conheça seus direitos e possa ajudar o Brasil a ter um sistema de saúde com muito mais qualidade (BRASIL, 2007).

O Pacto de Gestão do SUS estabelece claramente as responsabilidades de cada esfera de governo com o objetivo de diminuir as competências concorrentes. Esse pacto viabiliza a descentralização de atribuições 
da esfera federal (Ministério da Saúde) para a estadual e desta para a municipal, desburocratizando os processos normativos.

O pacto reforça a territorialização da saúde (GONDIM; MONKEN, 2008) como base organizacional do SUS, estruturando as regiões sanitárias e instituindo colegiados de gestão regional (controle social). Enfatiza as diretrizes para o sistema de financiamento público tripartite; busca alocar equitativamente os recursos; reforça as transferências fundo a fundo entre os gestores; integra o financiamento federal em grandes blocos e estabelece relações contratuais entre os poderes.

Tem como prioridade definir a responsabilidade sanitária de cada instância gestora do SUS e estabelecer as diretrizes de gestão do SUS, com ênfase em descentralização, regionalização, financiamento, programação pactuada e integrada, regulação, participação e controle social, planejamento, gestão do trabalho e educação na saúde. 


\section{Anexo C - Resumo das diretrizes da Política Nacional de Atenção Básica}

1. Realizar as ações de saúde em território adstrito - propor planejamento e programação que buscam as verdadeiras necessidades da comunidade e dos indivíduos, por se basear nas condições e características do território.

2. Atender integralmente o indivíduo e a comunidade - servir de porta de entrada do Sistema Único de Saúde para o usuário, de forma a oferecer acolhimento e resolutividade, de acordo com as demandas da área, promovendo formação de vínculos e participação social.

3. Realizar cadastramento da população adscrita - buscar a criação de vínculos dos indivíduos e comunidade com a unidade básica de saúde, de forma que possa ser referência de ações de saúde, garantindo continuidade no acompanhamento.

4. Realizar ações de forma integrada e multiprofissional - qualificar a assistência à saúde com vários profissionais integrados na prevenção e promoção da saúde, utilizando diversos saberes para melhor avaliar e assistir o indivíduo, as famílias e a comunidade.

5. Promover participação social - incentivar a presença e a participação dos envolvidos no processo saúde-doença, as quais acarretam melhores avaliações dos fatores que determinam e condicionam o cuidado à saúde, promovendo atuação dos sujeitos na tomada de decisões.

Fonte: Brasil (2012).
"A adscrição da clientela referese ao novo vínculo que se estabelece de modo permanente entre os grupos sociais, as equipes e as unidades de saúde. A territorialização aponta para a relação precisa que se estabelece mediante a definição do território e da população, o que implica o mapeamento e a segmentação da população por território" (SOUZA: HAMANN, 2009, p. 1327).

Acolhimento "é uma prática presente em todas as relações de cuidado, nos encontros reais entre trabalhadores de saúde e usuários, nos atos de receber e escutar as pessoas, podendo acontecer de formas variadas" (BRASIL, 2011, p. 19). 